Article

\title{
Impact of Water Solubility on Chemical Composition and Surface Structure of Two Generations of Bioceramic Root Canal Sealers
}

\author{
Sawsan T. Abu Zeid ${ }^{1,2, *(\mathbb{D})}$, Ruaa A. Alamoudi ${ }^{1}$ (D) and Abeer A. Mokeem Saleh ${ }^{1}$ \\ 1 Endodontic Department, Faculty of Dentistry, King Abdulaziz University, Jeddah 21589, Saudi Arabia; \\ ralamoudi1@kau.edu.sa (R.A.A.); aasaleh@kau.edu.sa (A.A.M.S.) \\ 2 Endodontic Department, Faculty of Dentistry, Cairo University, Giza 12613, Egypt \\ * Correspondence: sawsanabuzeid55@hotmail.com or sabzaid@kau.edu.sa
}

Citation: Abu Zeid, S.T.; Alamoudi, R.A.; Mokeem Saleh, A.A. Impact of Water Solubility on Chemical Composition and Surface Structure of Two Generations of Bioceramic Root Canal Sealers. Appl. Sci. 2022, 12, 873 https://doi.org/10.3390/app12020873

Academic Editor: Gianrico Spagnuolo

Received: 16 December 2021

Accepted: 12 January 2022

Published: 15 January 2022

Publisher's Note: MDPI stays neutral with regard to jurisdictional claims in published maps and institutional affiliations.

Copyright: (C) 2022 by the authors. Licensee MDPI, Basel, Switzerland. This article is an open access article distributed under the terms and conditions of the Creative Commons Attribution (CC BY) license (https:// creativecommons.org/licenses/by/ $4.0 /)$.

\begin{abstract}
Aimed to evaluate the effect of water solubility on chemical properties and surface structure of bioceramic-based (BC-HiFlow and BC-EndoSeqence) compared with resin-based (Adseal) root canal sealers. Fresh mix was inserted into polyethylene mold $(n=10)$ and subjected to Vicat needle to evaluate the setting time. The set discs were analyzed by Fourier transform infrared (FTIR) spectroscopy then immersed in deionized water for 1, 7, 14 and 28 days. The solubility\%, pH changes, released calcium $\left(\mathrm{Ca}^{2+}\right)$, phosphate $\left(\mathrm{PO}_{4}{ }^{3-}\right)$ and silicon $\left(\mathrm{Si}^{4+}\right)$ ions were evaluated after each immersion period. The discs were analyzed by scanning electron microscopy/Energy dispersed X-ray (SEM/EDX) before and after solubility test. Although FTIR detected similar composition of both bioceramic-sealers, BC-EndoSequence determined the prolonged setting times. At the end of solubility test, both bioceramic-sealers exhibited significant greater solubility $(>3 \%)$, alkaline $\mathrm{pH}(>11)$ at $p<0.001$. Adseal displayed the significant greatest $\mathrm{Ca}^{2+}$ and $\mathrm{PO}_{4}{ }^{3-}$ released, while BC-HiFlow displayed the significant greatest $\mathrm{Si}^{4+}$ release $(p<0.001)$. SEM revealed voids and pores on the surface of all tested sealers with the greatest value on Adseal surface. In conclusion, although both bioceramic-sealers had high solubility, BC-Hiflow complied the ISO standard regarding setting time and least surface micropores better than that of BC-EndoSequence.
\end{abstract}

Keywords: BC-sealers; setting time; solubility; $\mathrm{pH}$; chemical properties

\section{Introduction}

Root canal sealers are used during endodontic obturation to achieve a hermetic seal throughout the root canal system including minor discrepancies and canal irregularities [1]. Therefore, ideal endodontic sealers should prevent leakage, minimize the risk of bacterial invasion from the periapical tissues, and resolve the periapical lesion [1,2]. In addition, root canal sealer should be biocompatible, dimensionally stabile, set slowly to ensure sufficient working time, provide an excellent seal when set and provide an adequate adhesion to the canal walls. It also should be insoluble to tissue fluids [3].

Solubility is defined as material mass loss during certain immersion time in aqueous environment [4]. It is an undesirable physical property for root canal sealers. It can induce sealer degradation; creating gaps at sealer/dentin or sealer/gutta-percha interface which compromise the apical seal of the obturation system [5] and enhance bacterial leakage [5]. Solubility behavior is influenced by the setting time and $\mathrm{pH}$ of the sealer [6]. In fact, the degraded byproducts and the released particles induce changes in $\mathrm{pH}$ of the media and in the sealer surface morphology which may affect the biological property of the sealer $[7,8]$.

Nowadays, various endodontic sealers are available in the market, including sealers based on glass ionomer, calcium hydroxide, resin, zinc oxide eugenol, silicone, and bioceramic (BC)-based root canal sealers. BC-Endoequence sealer (Brasseler USA, Savannah, GA, USA) was the first bioceramic-based root canal sealer introduced in 2009 [9]. It is a 
premixed paste sealer composed of calcium, phosphate, and silicate. It is categorized as hydraulic calcium silicate cement as it sets in the presence of a moist environment [10]. It has the ability to form calcium hydroxide as a byproduct of hydration reaction [11], and is responsible for its alkaline $\mathrm{pH}$ inducing antibacterial properties [12]. It is a biocompatible, bioactive sealer and enhances the osteogenic potential $[10,13,14]$. Its nanoparticle size allows an excellent flow to the dentin wall and improve the sealing ability [9]. In addition, it is available in injectable syringe enhances easy method of delivery and application. Previous studies reported high solubility of EndoSequence sealer $[4,6,8]$ that exceeds the acceptable level of ISO [15].

Recently, a new BC- HiFlow sealer (Brasseler USA, Savannah, GA, USA) launched in the market, and it is compatible with heat generated during warm vertical compaction technique. Few studies were recently published on the effect of heat on its physico-chemical properties [16-18]. It claimed to be less soluble due to its fast setting [16]. More information about chemical changes of BC- HiFlow sealer when immersed in aqueous media are required. The purpose of this study was to evaluate the effect of water solubility on the chemical properties (setting time, $\mathrm{pH}$ and released calcium $\left(\mathrm{Ca}^{2+}\right)$, phosphate $\left(\mathrm{PO}_{4}{ }^{3-}\right)$ and silicon $\left(\mathrm{Si}^{4+}\right)$ ions) and surface structure of recent generation $\mathrm{BC}-\mathrm{HiFlow}$ versus old generation BC-EndoSeqence bioceramic-based root canal sealers. The null hypothesis was that there was no significant difference between both sealers.

\section{Materials and Method}

The materials used in this study were pre-injectable syringe of EndoSequence BCand HiFlow BC- Bioceramic-based root canal sealers (Brasseler USA, Savannah, GA, USA). Dual syringe paste/paste injectable resin-based root canal sealer-Adseal (META Biomed Co., Chungbuk, Korea) was used as a control.

\subsection{Setting Time}

The initial and final setting times of all sealers were measured using a Vicat needle apparatus (Jin-Ching-Her, Taiwan). Sealers were placed inside polyethylene molds of $10 \mathrm{~mm}$ diameter and $3 \mathrm{~mm}$ height $(\mathrm{n}=10)$. The premixed $\mathrm{BC}$-sealers were injected directly into the mold, while the Adseal was mixed according to the manufacture instructions and inserted inside the mold. The surface of freshly mixed sealer was subjected to Vicat needle of $10 \mathrm{~mm}$ diameter, $50 \mathrm{~mm}$ length and $100 \mathrm{gm}$ weight, at room temperature $\left(23 \pm 1^{\circ} \mathrm{C}\right)$. The initial and final setting times were recorded until no indentation of the needle [19].

\subsection{Solubility Test}

Polyethylene molds of $10 \mathrm{~mm}$ diameter and $2 \mathrm{~mm}$ height were filled with freshly mixed sealers $(\mathrm{n}=10)$. The procedure was performed according to specification number 57 of the American Dental Association (ADA) for root canal filling [15]. The molds were held between two glass slabs and stored in an incubator at $37^{\circ} \mathrm{C}$ and $100 \%$ humidity until sealer set. After complete setting, the original dry weight of each sample $\left(W_{0}\right)$ was measured using an electric balance (Model \#ZSA210, Scientech Inc., Boulder, CO, USA). Each sample was then stored in a vial containing $10 \mathrm{~mL}$ deionized water at $37^{\circ} \mathrm{C}$. At an interval incubation periods $(1,7,14$ and 28 days), the samples were removed from the vial, dried with filter paper overnight and reweighted $\left(W_{t}.\right)$. The percent of material loss (solubility \%) was calculated according to the following equation [20]:

$$
\text { The solubility } \%=\frac{W_{0}-W_{t 1}}{W_{0}} \times 100
$$

\section{3. $p H$ Changes}

After calibration of the $\mathrm{pH}$ meter (JENWAY-3510 $\mathrm{pH}$ meter, Bibby Scientific Ltd., Stone, Staffs, UK) with standard solutions at $\mathrm{pH} 4.0$ and 7.0 at a constant temperature 
$\left(25^{\circ} \mathrm{C}\right)$ [12], the $\mathrm{pH}$ of each solution at each immersion interval period $(1,7,14$, and 28 days $)$ was evaluated.

\subsection{Releasing Elements}

The releasing $\mathrm{Ca}^{2+}, \mathrm{PO}_{4}{ }^{3-}$ and $\mathrm{Si}^{4+}$ ions were determined in the immersing solution of each solubility interval period $\left(1,7,14\right.$ and 28 days). $\mathrm{For}^{\mathrm{Ca}^{2+}}$ release, the solution was analyzed by EDTA titration method [21]. For $\mathrm{PO}_{4}{ }^{3-}$ release, the colorimetric method with spectrophotometer (JENWAY- 6705 UV/Vis Spectrophotometer, Stone, Staffs, UK) [22] was used. For $\mathrm{Si}^{4+}$ release, Inductively Couple Plasma Optical Emission Spectrometer (ICP-OES, Agilent 5100, Santa Clara, CA, USA) was used.

\subsection{Fourier Transform Infra-Red (FTIR) Analysis}

The set sealers were subjected to FTIR spectroscopy (Vertex 80v, Bruker, Germany) to analyze their chemical composition. The spectra were scanned at $4000-400 \mathrm{~cm}^{-1}$ and $1 \mathrm{~cm}^{-1}$ resolution. To verify the data, each spectrum was scanned three times.

\subsection{Scanning Electron Microscope (SEM) and Energy Dispersive X-ray (EDX) Analysis}

The surface morphology and composition of each sealer were determined by examining the discs of the set sealer using SEM/EDX (Octane pro, Model 7.2/15252, EDAX. Ametek Material and analysis division, Mahwah, NJ, USA). The changes in surface morphology and composition, as a result of solubility test, were also evaluated by examining the samples at the end of solubility test (28 days).

\subsection{Statistical Analysis}

To compare between the investigate sealers, the data of setting time, solubility \%, $\mathrm{pH}$ changes, releasing elements and EDX analysis was statistically analysed by One-Way ANOVA and Post-hoc Tukey HSD tests using SPSS software (Version 16.0; SPSS, Inc., Chicago, IL, USA) at significance level of $5 \%$.

\section{Results}

\subsection{Setting Time}

Prolonged initial setting time was significantly recorded by BC-EndoSequence at $p<0.001$, while shortest initial setting time was recorded by Adseal with no significant difference with $\mathrm{BC}$-HiFlow at $p=0.194$. In regard to the final setting time, Adseal recorded the significant fastest setting time followed by BC-HiFlow $(p<0.001)$. BC-EndoSequence showed $0.5 \mathrm{~mm}$ indentation after $123 \pm 10.3 \mathrm{hrs}$ that persisted for 3 months (Table 1).

Table 1. Represents the means \pm Standard deviation values of initial and final setting times of the three tested sealers.

\begin{tabular}{lcccc}
\hline & & BC-HiFlow & BC-EndoSequence & Adseal \\
\hline \multirow{2}{*}{ Setting Time } & Initial (hrs) & $4.12 \pm 0.12 \neq$ & $44.2 \pm 6.3^{*}$ & $1.22 \pm 0.19 \neq$ \\
& Final (hrs) & $37 \pm 5.46$ & $<123 \pm 10.3^{*}$ & $4.7 \pm 0.44 \dagger$
\end{tabular}

$\left({ }^{*}\right)$ is the significant greatest value while $(\dagger)$ is the significant lowest value at $p<0.001 .(\neq)$ indicates no significant difference between the sealers of the same symbol at $p>0.05$.

\subsection{Solubility Test}

The BC-Hiflow showed the significant lowest solubility \% in all experimental immersion times, while the BC-EndoSequence showed the highest values that increases with time $(p<0.001)$. On the contrary, Adseal displayed gradual gain weight that declined after 21 days at $p<0.001$ (Figure 1A). 

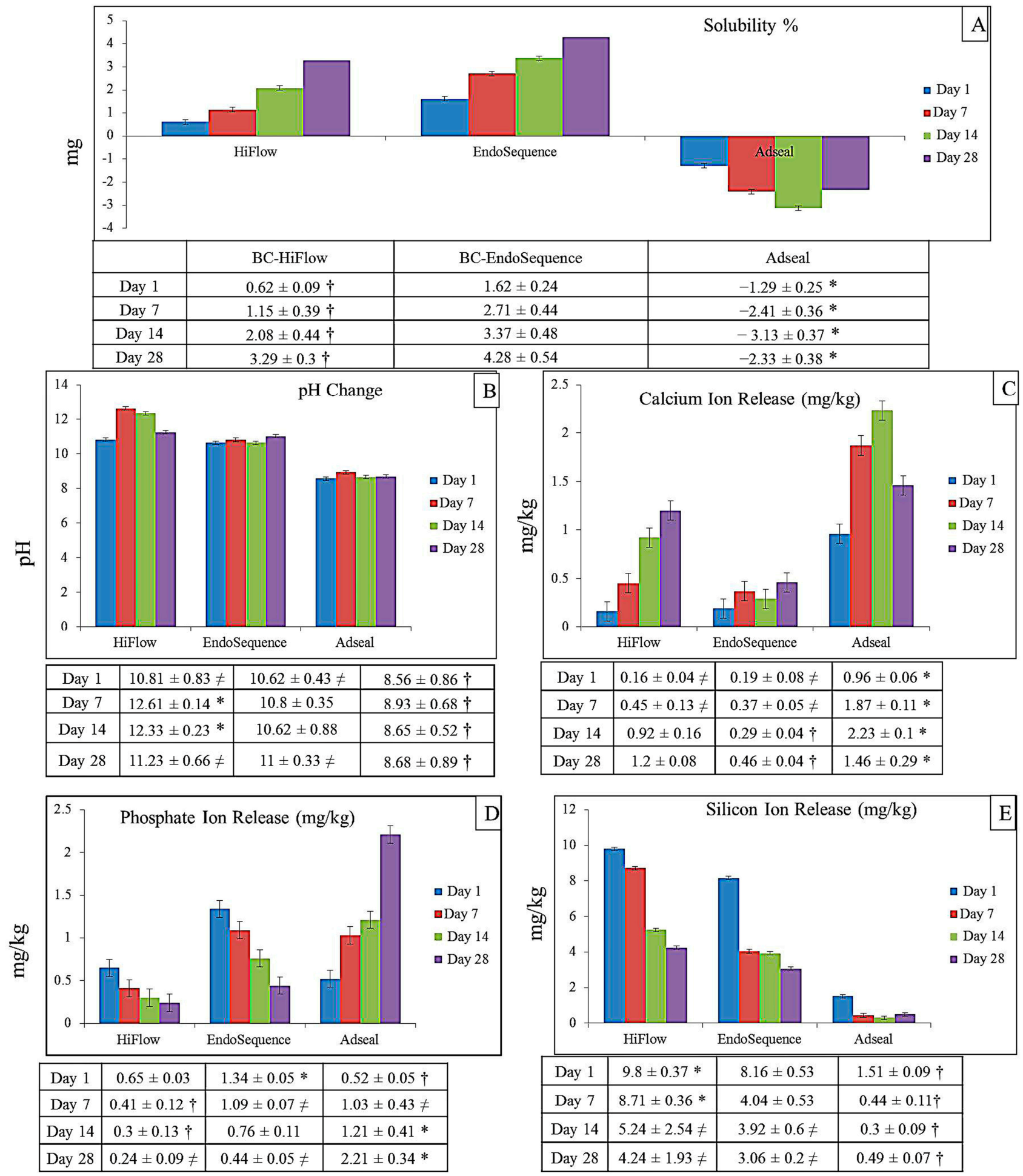

Figure 1. Represents the mean \pm standard deviation values of (A) solubility \%, (B) $\mathrm{pH}$ changes, (C) calcium, (D) phosphate and (E) silicon ions released of the investigated sealers among the experiment immersion times. $\left(^{*}\right)$ is the significant greatest value while $(+)$ is the significant lowest value at $p<0.001 .(\neq)$ indicates no significant difference between the sealers of the same symbol at $p>0.05$. 


\section{3. $\mathrm{pH}$ Analysis}

The result of the $\mathrm{pH}$ analysis for all tested sealers in all time periods was shown in (Figure 1B). Both BC-sealers determined significant high alkaline $\mathrm{pH}$ (range between 10.6 and 12.6), as compared to Adseal $(\approx 8.5)$, at $p<0.001$. The $\mathrm{pH}$ of BC-HiFlow increased from day 1 to day 7 then gradually decreased up to day 28. BC-EndoSequence showed continuous increasing in the $\mathrm{pH}$ from day 1 up to day 28 . Adseal exhibited the significant weak alkaline $\mathrm{pH}$ throughout the experimental periods.

\subsection{Releasing Elements}

\subsubsection{Calcium Ion Release}

Adseal exhibited the significant high amount of $\mathrm{Ca}^{2+}$ release compared to the BCsealers $(p<0.001)$. Meanwhile, BC-EndoSequence recorded the significant lowest values of $\mathrm{Ca}^{2+}$ release, with no significant difference versus BC-HiFlow within the first 7 days $(p>0.05)$, while a significant difference was detected after the 7th day $(p<0.001)$ (Figure $1 C)$.

\subsubsection{Phosphate Ion Release}

BC-HiFlow and BC-EndoSequence sealers showed gradual reduction in the amount of $\mathrm{PO}_{4}{ }^{3+}$ release from day 1 up to day 28 , whereas a gradual increase was recorded by the Adseal (Figure 1D). The significant greatest value was recorded by BC-EndoSequence at day 1 and 7, whereas Adseal showed the significant greatest values at day 14 and 28 at $p<0.001$. The significant lowest value was obtained by BC-HiFlow among all experimental immersion times at $p<0.001$.

\subsubsection{Silicon Ion Release}

In all the three sealers, the amount of $\mathrm{Si}^{4+}$ release was gradually decreased by time. The significant amount of releasing $\mathrm{Si}^{4+}$, from day 1 to day 28, was obtained by BC-HiFlow followed by BC-EndoSequence at $p<0.001$, while the significant lowest values were obtained by Adseal at $p<0.001$ (Figure 1E).

\subsection{FTIR Spectroscopy}

The spectra of BC-HiFlow (Figure 2A,B) and BC-EndoSequence (Figure 2C,D) revealed similar composition of both $\mathrm{BC}$-sealers with variable band intensity. They detected bands of calcium hydroxide $\approx 3640 \mathrm{~cm}^{-1}$ [11,23-26], OH of absorbent water associated with hydration reaction of sealer $\approx 3400 \mathrm{~cm}^{-1}[24,25,27], \mathrm{C}-\mathrm{H}$ and $\mathrm{OH}$ - of organic filler (polyethylene glycol) at $2980-2800$ and $\approx 1635 \mathrm{~cm}^{-1}[23,25,27]$, carbonate $\left(\mathrm{CO}_{3}{ }^{2-}\right)$ at 1420 and $874 \mathrm{~cm}^{-1}[23,24,28]$, phosphate bands of $v_{3} \mathrm{PO}_{4}{ }^{3-} \approx 1066[27,29,30]$ and at $974 \mathrm{~cm}^{-1}$ [28], $v_{4} \mathrm{PO}_{4}{ }^{3-}$ at $665 \mathrm{~cm}^{-1}[27,29,30], \mathrm{SiO}_{4}{ }^{4-}$ of calcium silicate incorporated with $v_{3} \mathrm{PO}_{4}{ }^{3-}$, calcite at 974 and $874 \mathrm{~cm}^{-1}$, respectively [28,31], $v_{4} \mathrm{SiO}_{4} \approx 750 \mathrm{~cm}^{-1}, \mathrm{SiO}_{4}{ }^{4-}$ bending mode of tricalcium silicate $\left(\mathrm{C}_{3} \mathrm{~S}\right) \approx 570 \mathrm{~cm}^{-1}$ and dicalcium silicate $\left(\mathrm{C}_{2} \mathrm{~S}\right)$ at 502 and $494 \mathrm{~cm}^{-1}$ [25], Si-O- stretching mode of calcium silicate hydrate (CSH) at $450 \mathrm{~cm}^{-1}[25,28,32]$.

The spectra of Adseal showed different composition. It detected intense bands of $\mathrm{C}=\mathrm{O}$ of organic filler $\approx 1635 \mathrm{~cm}^{-1}[23,25]$ carbonate band $\left(\mathrm{CO}_{3}{ }^{2-}\right)$ at $1458 \mathrm{~cm}^{-1}$, silicate group (Si-O) at $1113 \mathrm{~cm}^{-1}$ [25], phosphate bands ( $\mathrm{v}_{3}$ and $\mathrm{v}_{4} \mathrm{PO}$ ) at 1035 and $680-560 \mathrm{~cm}^{-1}$ [30], respectively, and polymerized silicon ( $\mathrm{SiO}$ ) at $420 \mathrm{~cm}^{-1}$ [25], (Figure 2E,F).

\subsection{SEM/EDX}

The surfaces of both BC-HiFlow (Figure 3A) and BC-EndoSequence (Figure 3B) had a nearly similar structure before immersion in water. They showed a homogenous structure of granular mass. The surface of Adseal showed uniform, homogenous structure of irregular small particles (Figure 3C). The bright particles of radio-opacifiers $\left(\mathrm{ZrO}_{2}\right)$ were distributed over the surface of all sealers. The intra-granular voids and pores were detected in all sealers where more prominent in Adseal surface. 

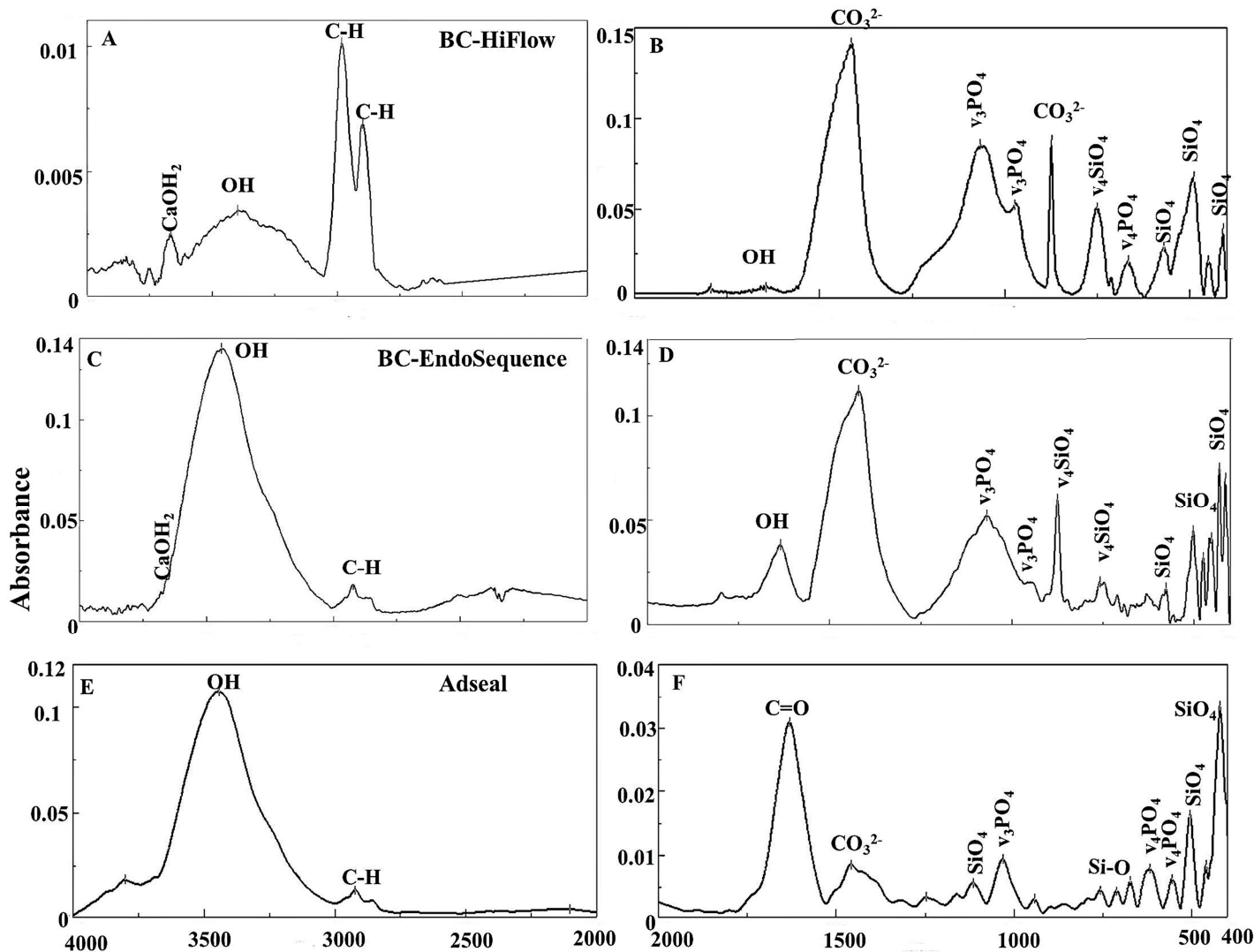

Wavenumber $\left[\mathrm{cm}^{-1}\right]$

Figure 2. FTIR spectra at 4000-2000 and 2000-400 $\mathrm{cm}^{-1}$ of BC-HiFlow (A,B), BC-EndoSequence (C,D) and Adseal $(\mathbf{E}, \mathbf{F})$ respectively showed their composition.

The elemental analysis determined that all tested sealers contain carbon $(\mathrm{C})$, oxygen $(\mathrm{O})$, silicon $(\mathrm{Si})$, phosphorous $(\mathrm{P})$ and calcium $(\mathrm{Ca})$ peaks with different wt.\% (Figure 3D-F). Before immersing (day 0), the surface of the set sealers contained high $C$ peak and low $\mathrm{O}$ and Ca peaks $(p<0.001)$. The significant greater $\mathrm{C}, \mathrm{P}$ peaks were recorded by Adseal, while the significant high Ca peak was recorded by BC-EndoSequence $(p<0.001)$. The Si peak was significantly high in BC-HiFlow and low in BC-EndoSequence. The $P$ peak was significantly high in Adseal at $p<0.001$, while low in both BC-sealers with no significant difference between them $(p=0.751)$. As a radio-opacifier, $\mathrm{BC}$-HiFlow contains significant higher zirconium $(\mathrm{Zr})$ peak than BC-EndoSequence, while Adseal contained bismuth (Bi) peak $(p<0.001)$

The development of porous hierarchical structure (calcium carbonate) was shown on BC-HiFlow surface. The spheroidal and rod-like (aragonite) crystalline structure was detected over the BC-EndoSequence surface with the development of cubic shaped crystals (calcium hydroxide) (Figure 3K), while rectangular shaped-crystals (calcium phosphate) were shown on the Adseal surface after water immersion (Figure 3G-I). The voids and pores were predominant on the surfaces of all tested sealers with different distribution at the end of water immersion time (at day 28), (Figure 3J-L). The greatest value was observed on the Adseal surface (Figure 3L).

After immersion in water (day 28), the elemental analysis (EDX) of BC-HiFlow (Figure $3 \mathrm{M}$ ) showed decrease in $\mathrm{C}$, Si and $\mathrm{Zr}$, while significantly increase in $\mathrm{P}$ and $\mathrm{Ca}$ peaks $(p<0.001)$. The spectra of BC-EndoSequence (Figure $3 \mathrm{~N}$ ) showed marked decrease in C, but significant increase in Si, P, Zr and Ca. The spectra of Adseal (Figure 3O) showed significant increase in $\mathrm{Si}$ and $\mathrm{P}$ peak, while decrease in $\mathrm{Bi}(p<0.001)$, and no significant changes in Ca peak $(p>0.05)$. 


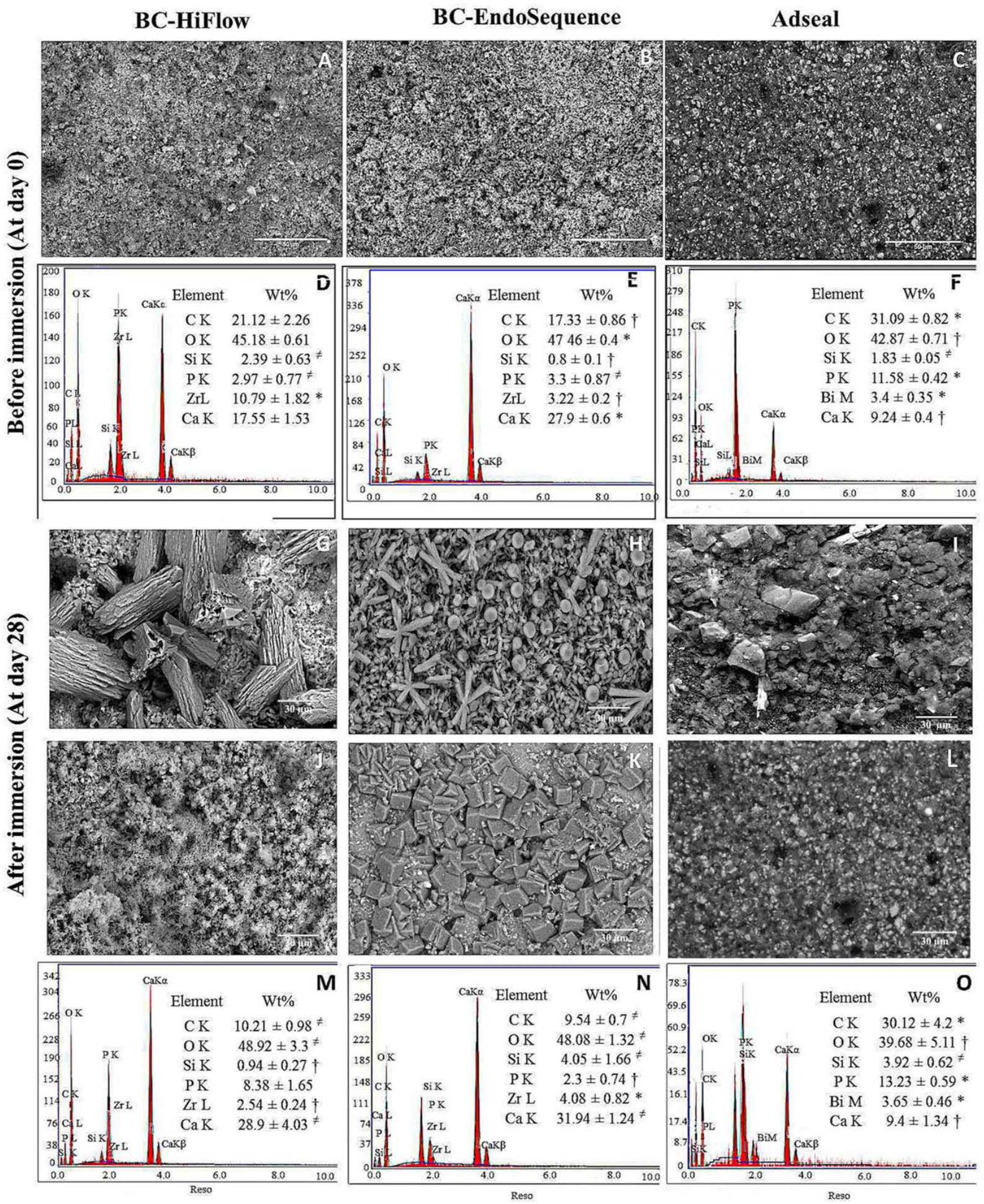

Figure 3. SEM/EDX analysis of the three sealers before (A-F) and after 28 days $(\mathbf{G}-\mathbf{O})$ immersion in water. $\left({ }^{*}\right)$ is the significant greatest value while $(\dagger)$ is the significant lowest value at $p<0.001$. $(\neq)$ indicates there is no significant difference between sealers with the same symbol at $p>0.05$.

\section{Discussion}

Recently, a new formula of bioceramic (BC-HiFlow) sealer was manufactured to resist the high temperature subjected during warm vertical compaction technique. It is important for clinician to understand the behaviour and performance of root canal sealer under clinical situation. The sealer solubility has an impact on the longevity of endodontic treatment. 
It could induce sealer degradation; compromising the apical seal, and enhance bacterial leakage [5].

The current study investigated the impact of water solubility on the chemical properties of the first (BC-EndoSequence) versus the recent (BC-HiFlow) generation of bioceramic sealers. Although both sealers have nearly similar composition [10], their chemical behaviour and surface morphology (particularly after water immersion) have been currently reported to be different. Hence, the null hypothesis was rejected.

Both BC-sealers displayed solubility\% with the significant greater values obtained by BC-EndoSequence greater than acceptable level of ISO [18], within 21 days (Figure 1A). The high solubility was previously reported by both BC-sealers in other studies which was either in accordance with acceptable limit (3\% mass fraction) [33] or more exaggerated than the recommended with ISO $[4,6,8,12,34]$. The present result recorded the solubility values within an acceptable limit within the first 14 or 21 days for BC-Endosequence or BC-HiFlow, respectively (Figure 1A). This discrepancy of current versus previous findings may be due to the solubility test was performed after one month until maximum material setting. Conversely, Adseal underwent to gain weight that gradually increased then declined after 21 days. This finding is in accordance with previous study [35]. Adseal resin-based sealer was used as a control sealer due to its availability. It is also composed of calcium phosphate comparable to bioceramic based sealers. Moreover, several studies reported good solubility property similar to other resin based sealer such as AH-plus [36].

The sealer solubility seems to be influenced by multiple factors, setting time and composition. In turn, it may induce greater release of elements and $\mathrm{pH}$ changes. According to Grossmann, slow initial setting without further prolonged final setting and alkaline $\mathrm{pH}$ are essential properties required for an ideal root canal sealer [3,37]. BC-EndoSequence displayed the significant prolonged initial setting time and failed to complete set until 3 months (Table 1). However, BC-HiFlow recorded 4.12 and $37 \mathrm{hrs}$ for initial and final setting time, respectively. The prolonged setting time of BC-Endosequence was previously reported, where it was exceeding one month [38]. It was suggested that the BC-EndoSequence, as a hydraulic sealer, did not set in $>95 \%$ humid incubator [35] and it set in a moist environment similar to root canal system that contains fluid inside dentinal tubules [4]. There were few studies related to BC-HiFlow. The current finding was nearly similar to two studies which recorded 4-6 and 31-33 hrs for initial and final setting, respectively [16,39]. In addition, they showed no significant difference between setting time of BC-EndoSequence and BC-Hiflow after heat application [16,39]. Thus, heat seems to accelerate the hydration reaction $[18,39]$.

Reciprocal reaction was noted between solubility, released by-products, and $\mathrm{pH}$. Sealer with high alkaline $\mathrm{pH}$ and $\mathrm{Ca}^{2+}$ release consider as favourable root canal sealers to enhance antibacterial and osteogenic activity $[7,13,33,40-42]$. Both BC-sealers exhibit high alkaline $\mathrm{pH}$ range between 10.5 and 12, with the maximum value at 21 days for BC-HiFlow, while maintained continuous increased up to 28 days for BC-EndoSequence (Figure 1B). Similar $\mathrm{pH}$ values of BC-EndoSequence [18,33,43] and BC-HiFlow sealers [39] were previously reported. However, one study reported lower value for BC-HiFlow that did not exceed 8.5 among 28 days [16]. Their alkalinity was increased consequent to increase the solubility and increasing the releasing $\mathrm{Ca}^{2+}$ among the successive experimental periods.

The $\mathrm{pH}$ value seems to be associated with the setting time. Although both $\mathrm{BC}$-sealers display high alkaline $\mathrm{pH}$ among all the experimental periods, gradual decline of this value by BC-HiFlow after 7 days was noted and may be attributed to its fast setting within this time. However, BC-EndoSequence represents further increase in $\mathrm{pH}$ up to 28 days that may be attributed to its prolonged final setting time which extended over 3 months.

On the other hand, Silva et al. 2021 reported that high alkaline environment reduced the solubility of the BC-EndoSequence sealer [6]. As a result of the hydration reaction of the calcium silicate-based sealers, calcium hydroxide was formed and dissociated into hydroxyl ions $\left(\mathrm{OH}^{-}\right)$. With high alkaline medium, supersaturation of $\mathrm{OH}^{-}$may reduce further ion dissociation and thus reduce sealer solubility [6]. However, Adseal displayed weak alkaline $\mathrm{pH}(\approx 8.5)$ among all experimental periods. It was suggested that the low alkalinity was 
favourable for epoxy resin sealer as it eliminates the corrosion and degradation of sealer particles and in turn reduce its solubility [6].

Assuming the similar composition of both BC-sealers, FTIR analysis revealed similar composition of both sealers with different band intensity indicating the variable concentration of their constituents, which related to their different chemical properties. The high solubility may be attributed to the $\mathrm{Ca}(\mathrm{OH})_{2}$ content [38] that was detected with high band intensity in FTIR spectra of BC-HiFlow (Figure 2A). Furthermore, the high intensity of $\mathrm{CH}$ of organic filler indicates an increase in the setting accelerating agent while the decrease of $\mathrm{OH}$ - (at 3400 and $\approx 1650 \mathrm{~cm}^{-1}$ ) bands indicates the consumption of water during hydration reaction. The high intense $\mathrm{v}_{4} \mathrm{SiO}_{4} \approx 750$ and $450 \mathrm{~cm}^{-1}$ indicates the formation of polymerized calcium silicate hydrate (CSH) $[25,28,32]$. These findings explained the faster setting of $\mathrm{BC}$-HiFlow compared with spectra of $\mathrm{BC}$-Endosequence (Figure 2B). However, the spectra of BC-Endosequence detected high intensity of $\mathrm{v}_{4} \mathrm{SiO}_{4}$ of $\mathrm{C}_{2} \mathrm{~S}$ at $874 \mathrm{~cm}^{-1}$ indicating greater content of unreacted particles [25], which may be related to its prolonged setting time and possibility of higher solubility.

On the contrast, Adseal contained insoluble resin matrix that formed during polymerization reaction of amine group of epoxide groups having covalent cross-linked bond that resist the solubility. Furthermore, gain weight was initially obtained by Adseal that may be attributed to initial water sorption of resinous matrix during polymerization expansion $[5,35]$. However, Adseal exhibited delay weight loss after 21 days and that may be attributed to degradation of unreacted particles [44].

The solubility is considered as prerequisite for leaching particles. Since calcium silicate is the main constituent in BC-sealer, and calcium phosphate in Adseal, the leachable $\mathrm{Si}^{4+}$ and $\mathrm{PO}_{4}{ }^{3-}$ are respectively critical for these sealers. It confirmed by the current study where significant greater released of $\mathrm{Si}^{4+}$ was detected in BC-HiFlow followed by BC-EndoSequence. BC-HiFlow contained greater wt.\% of Si than BC-EndoSequence (Figure 3D,E). Meanwhile, Adseal released greater $\mathrm{PO}_{4}{ }^{3-}$ that attributed to its greater $\mathrm{P}$ wt.\% (Figure 3F). These leachable particles are correlated to the formation of micropores over the sealer surface at the end of the solubility test. Although the greater $\mathrm{Si}^{4+}$ released by $\mathrm{BC}$-sealers, the micropores were showed with lower values. It may be attributed to the crystalline phases detected on their surface when immersed in water (Figure 3G,H).

\section{Conclusions}

Upon the circumstances of this study, both BC-sealers presented greater solubility with significant greater values obtained by $\mathrm{BC}$-EndoSequence that may be correlated with its prolonged setting time. Furthermore, BC-EndoSequence did not compete with the ISO standard related to solubility $\%$ that exceeds the acceptable limit within 21 days. It did not completely set at $100 \%$ humid incubator in up to 3 months. Yet, BC-HiFlow presented solubility\% nearly within acceptable ISO limit. In addition, surface crystallization of BC-sealers after water immersion seems to resist surface solubility.

Author Contributions: Conceptualization, S.T.A.Z.; methodology, S.T.A.Z.; software, S.T.A.Z., R.A.A. and A.A.M.S.; validation, S.T.A.Z., R.A.A. and A.A.M.S.; formal analysis, S.T.A.Z.; investigation, S.T.A.Z., R.A.A. and A.A.M.S.; resources, S.T.A.Z.; data curation, S.T.A.Z.; writing-original draft preparation, S.T.A.Z.; writing-review and editing, R.A.A. and A.A.M.S.; visualization, R.A.A.; supervision, S.T.A.Z.; project administration, R.A.A.; funding acquisition, R.A.A. and A.A.M.S. All authors have read and agreed to the published version of the manuscript.

Funding: This project was funded by the Deanship of Scientific Research (DSR) at King Abdulaziz University, Jeddah, under grant no. (G: 14-165-1441). The authors, therefore, acknowledge with thanks DSR for technical and financial support.

Institutional Review Board Statement: This clinical study was approved by the Ethical Committee of King Abdulaziz University (\#285-09-21).

Data Availability Statement: The data presented in this study are available to all readers according to "MDPI Research Data Policies". 
Conflicts of Interest: The authors declare no conflict of interest.

\section{References}

1. Branstetter, J.; von Fraunhofer, J. The physical properties and sealing action of endodontic sealer cements: A review of the literature. J. Endod. 1982, 8, 312-316. [CrossRef]

2. Glickman, G.; Walton, R. Endodontics: Princiles and Practice, 4th ed.; Obturation, M.T., Walton, R., Eds.; Elsevier: St. Louis, MO, USA, 2009; pp. 305-307.

3. Lombardi, V. Grossman Endodontic Practice, 13th ed.; Henry Kimpton Publishers: Philadelphia, PA, USA, 2014 ; pp. 367-369.

4. Elyassi, Y.; Moinzadeh, A.T.; Kleverlaan, C.J. Characterization of Leachates from 6 Root Canal Sealers. J. Endod. 2019, 45, 623-627. [CrossRef] [PubMed]

5. Carvalho-Junior, J.R.; Correr-Sobrinho, L.; Correr, A.B.; Sinhoreti, M.; Consani, S.; Sousa-Neto, M.D. Solubility and Dimensional Change after Setting of Root Canal Sealers: A Proposal for Smaller Dimensions of Test Samples. J. Endod. 2007, 33, 1110-1116. [CrossRef] [PubMed]

6. Silva, E.; Ferreira, C.; Pinto, K.; Barbosa, A.; Colaço, M.; Sassone, L. Influence of variations in the environmental pH on the solubility and water sorption of a calcium silicate-based root canal sealer. Int. Endod. J. 2021, 54, 1394-1402. [CrossRef] [PubMed]

7. Desai, S.; Chandler, N. Calcium Hydroxide-Based Root Canal Sealers: A Review. J. Endod. 2009, 35, 475-480. [CrossRef]

8. Torres, F.; Zordan-Bronzel, C.; Guerreiro-Tanomaru, J.; Chavez-Andrade, G.; Pinto, J.; Tanomaru-Filho, M. Effect of immersion in distilled water or phosphate-buffered saline on the solubility, volumetric change and presence of voids within new calcium silicate-based root canal sealers. Int. Endod. J. 2020, 53, 385-391. [CrossRef] [PubMed]

9. Koch, K.; Brave, D. Bioceramic technology-The game changer in endodontics. Endod. Prac. 2009, 2, 17-21.

10. Drukteinis, S.; Camilleri, J. Bioceramic Materials in Clinical Endodontics; Springer: Berlin/Heidelberg, Germany, 2021.

11. Abu Zeid, S.T.; Saleh, A.A.M.; Khafagi, M.G.E.-D.; Neel, E.A.A. Setting reaction of new bioceramic root canal sealers. Spectrosc. Lett. 2018, 51, 426-430. [CrossRef]

12. Abu Zeid, S.T.H.; Saleh, A.A.Y.M. Solubility, pH Changes and Releasing Elements of Different Bioceramic and Mineral Trioxide Aggregate Root Canal Sealers Comparative Study. J. Trauma Treat 2015, 4, 1-4.

13. Edrees, H.Y.; Abu Zeid, S.T.; Atta, H.M.; AlQriqri, M.A. Induction of Osteogenic Differentiation of Mesenchymal Stem Cells by Bioceramic Root Repair Material. Materials 2019, 12, 2311. [CrossRef]

14. Abu Zeid, S.T.; AlAmoudi, R.A.; Neel, E.A.A.; Saleh, A.A.M. Morphological and Spectroscopic Study of an Apatite Layer Induced by Fast-Set Versus Regular-Set EndoSequence Root Repair Materials. Materials 2019, 12, 3678. [CrossRef]

15. American National Standards Institute. American Dental Association Specification no. 57 for endodontic filling materials. J. Am. Dent. Assoc. 2000, 108, 88.

16. Antunes, T.; Janini, A.; Pelepenko, L.; Abuna, G.; Paiva, E.; Sinhoreti, M.; Raimundo, I., Jr.; Gomes, B.; Denes, T.; Janini, A.; et al. Heating stability, physical and chemical analysis of calcium silicateiano, endodontic sealers. Int. Endod. J. 2021, 54, 1175-1188. [CrossRef]

17. Donnermeyer, D.; Ibing, M.; Bürklein, S.; Weber, I.; Reitze, M.; Schäfer, E. Physico-Chemical Investigation of Endodontic Sealers Exposed to Simulated Intracanal Heat Application: Hydraulic Calcium Silicate-Based Sealers. Materials 2021, 14, 728. [CrossRef] [PubMed]

18. Yamauchi, S.; Watanabe, S.; Okiji, T. Effects of heating on the physical properties of premixed calcium silicate-based root canal sealers. J. Oral Sci. 2021, 63, 65-69. [CrossRef] [PubMed]

19. Astm, C. Standard test methods for time of setting of hydraulic cement by Vicat needle, 1995.

20. McMichen, F.; Pearson, G.; Rahbaran, S.; Gulabivala, K. A comparative study of selected physical properties of five root-canal sealers. Int. Endod. J. 2003, 36, 629-635. [CrossRef]

21. Kim, J.; Vipulanandan, C. Effect of $\mathrm{pH}$, sulfate and sodium on the EDTA titration of calcium. Cem. Concr. Res. 2003, 33, 621-627. [CrossRef]

22. Mussa, S.B.; Elferjani, H.S.; Haroun, F.A.; Abdelnabi, F.F. Determination of available nitrate, phosphate and sulfate in soil samples. Int. J. PharmTech Res. 2009, 1, 598-604.

23. Blesa, M.; Miranda, J.; Moliner, R. Micro-FTIR study of the blend of humates with calcium hydroxide used to prepare smokeless fuel briquettes. Vib. Spectrosc. 2003, 33, 31-35. [CrossRef]

24. Li, Q.; Coleman, N. The hydration chemistry of ProRoot MTA. Dent. Mater. J. 2015, 34, 458-465. [CrossRef] [PubMed]

25. Okamura, T.; Chen, L.; Tsumano, N.; Ikeda, C.; Komasa, S.; Tominaga, K.; Hashimoto, Y. Biocompatibility of a High-Plasticity, Calcium Silicate-Based, Ready-to-Use Material. Materials 2020, 13, 4770. [CrossRef]

26. Ylmén, R.; Jäglid, U.; Steenari, B.-M.; Panas, I. Early hydration and setting of Portland cement monitored by IR, SEM and Vicat techniques. Cem. Concr. Res. 2009, 39, 433-439. [CrossRef]

27. Chen, B.; Haapasalo, M.; Mobuchon, C.; Li, X.; Ma, J.; Shen, Y. Cytotoxicity and the Effect of Temperature on Physical Properties and Chemical Composition of a New Calcium Silicate-based Root Canal Sealer. J. Endod. 2020, 46, 531-538. [CrossRef] [PubMed]

28. Voicu, G.; Bădănoiu, A.I.; Ghiţulică, C.D.; Andronescu, E. Sol-Gel synthesis of white mineral trioxide aggregate with potential use as biocement. Dig. J. Nanomater. Biostructures 2012, 7, 1639-1646.

29. Radev, L.; Hristov, V.; Michailova, I.; Fernandes, H.M.V.; Salvado, M.I.M. In vitro bioactivity of biphasic calcium phosphate silicate glass-ceramic in $\mathrm{CaO}-\mathrm{SiO}_{2}-\mathrm{P}_{2} \mathrm{O}_{5}$ system. Process. Appl. Ceram. 2010, 4, 15-24. [CrossRef] 
30. Jayasree, R.; Kumar, T.S.; Kavya, K.P.S.; Nankar, P.; Mukesh, D. Self setting bone cement formulations based on egg shell derived tetracalcium phosphate bioceramics. Bioceram. Dev. Appl. 2015, 5, 2.

31. Gandolfi, M.G.; Taddei, P.; Tinti, A.; Prati, C. Apatite-forming ability (bioactivity) of ProRoot MTA. Int. Endod. J. 2010, 43, 917-929. [CrossRef]

32. Taddei, P.; Modena, E.; Tinti, A.; Siboni, F.; Prati, C.; Gandolfi, M.G. Vibrational investigation of calcium-silicate cements for endodontics in simulated body fluids. J. Mol. Struct. 2011, 993, 367-375. [CrossRef]

33. Zhou, H.-M.; Shen, Y.; Zheng, W.; Li, L.; Zheng, Y.F.; Haapasalo, M. Physical Properties of 5 Root Canal Sealers. J. Endod. 2013, 39, 1281-1286. [CrossRef] [PubMed]

34. Borges, R.; Sousa-Neto, M.D.; Versiani, M.A.; Rached-Júnior, F.A.; De-Deus, G.; Miranda, C.E.S.; Pécora, J.D. Changes in the surface of four calcium silicate-containing endodontic materials and an epoxy resin-based sealer after a solubility test. Int. Endod. J. 2012, 45, 419-428. [CrossRef]

35. Lee, J.K.; Kwak, S.W.; Ha, J.-H.; Lee, W.; Kim, H.-C. Physicochemical properties of epoxy resin-based and bioceramic-based root canal sealers. Bioinorg. Chem Appl. 2017, 2017, 2582849. [CrossRef]

36. Marciano, M.A.; Guimarães, B.M.; Ordinola-Zapata, R.; Bramante, C.; Cavenago, B.; Garcia, R.B.; Bernardineli, N.; Andrade, F.; Moraes, I.G.; Duarte, M.A.H. Physical Properties and Interfacial Adaptation of Three Epoxy Resin-based Sealers. J. Endod. 2011, 37, 1417-1421. [CrossRef]

37. Grossman, L.I.; Oliet, S.; Del Rio, C. Endodontic Practice, 11th ed.; Lea \& Febiger: Philadelphia, PA, USA, 1988 ; pp. $326-327$.

38. Komabayashi, T.; Colmenar, D.; Cvach, N.; Bhat, A.; Primus, C.; Imai, Y. Comprehensive review of current endodontic sealers. Dent. Mater. J. 2020, 39, 703-720. [CrossRef] [PubMed]

39. Mann, A. Evaluation of the Physico-Chemical and Biological Properties of a New Bioceramic Sealer; The University of Texas School of Dentistry at Houston, ProQuest LLC: Ann Arbor, MI, USA, 2020.

40. Wang, Z. Bioceramic materials in endodontics. Endod. Top. 2015, 32, 3-30. [CrossRef]

41. McHugh, C.P.; Zhang, P.; Michalek, S.; Eleazer, P.D. pH required to kill Enterococcus faecalis in vitro. J. Endod. 2004, 30, 218-219. [CrossRef] [PubMed]

42. Urban, K.; Neuhaus, J.; Donnermeyer, D.; Schäfer, E.; Dammaschke, T. Solubility and pH Value of 3 Different Root Canal Sealers: A Long-term Investigation. J. Endod. 2018, 44, 1736-1740. [CrossRef]

43. De Miranda Candeiro, G.T.; Correia, F.C.; Duarte, M.A.H.; Ribeiro-Siqueira, D.C.; Gavini, G. Evaluation of Radiopacity, pH, Release of Calcium Ions, and Flow of a Bioceramic Root Canal Sealer. J. Endod. 2012, 38, 842-845. [CrossRef] [PubMed]

44. Rakhshan, V.; Azadi, N.; Fallahdoost, A.; Mehrvarzfar, P.; Rakhshan, H. A four-week solubility assessment of AH-26 and four new root canal sealers. Dent. Res. J. 2012, 9, 31-35. [CrossRef] 